\title{
Conferencia de Medellín y familia latinoamericana. El modelo eclesiológico como nuevo paradigma para el siglo $x \mathrm{xI}^{*}$
}

\author{
María del Pilar Mesa Beleño*
}

Recepción: 17 de abril de 2020 • Aprobación: 13 de mayo de 2020

\section{Resumen}

La Segunda Conferencia General del Episcopado Latinoamericano, celebrada en la ciudad de Medellín, Colombia, en el año de 1968, fue considerada el "Concilio Vaticano II en América Latina", pues hizo la inculturización de este en el nuevo continente. Este artículo toma, del tercer capítulo de la Conferencia (familia y demografía), el tema de la familia, como formadora de personas, educadora en la fe y promotora de desarrollo, y selecciona cinco conceptos claves (salvación, santidad, vida sacramental, unidad y comunidad de fe), para, luego, hacer un paralelo con los modelos eclesiológicos del tratado de eclesiología propuesto por el Concilio Vaticano II; finalmente, propone a la familia latinoamericana como modelo eclesiológico que afronta los retos propuestos por el siglo xxI.

Palabras clave: familia latinoamericana, Segunda Conferencia General del Episcopado Latinoamericano, Concilio Vaticano II, modelo eclesiológico, eclesiología, siglo xxI.

Artículo de reflexión. Citar como: Mesa Beleño, M. P. (2020). Conferencia de Medellín y familia latinoamericana. El modo eclesiológico como nuevo paradigma del siglo xxI. Albertus Magnus, XI(2), 185-201. https://doi.org/10.15332/25005413.6404

* Universidad Católica Luis Amigó, Medellín, Colombia. https://orcid.org/0000-00019906-8053. Correo electrónico: pilar.mesa@upb.edu.co 


\title{
Medellín Conference and Latin American family. Ecclesiological model as a new paradigm for the 21st century
}

\begin{abstract}
The Second General Conference of the Latin American Episcopate, held in the city of Medellín, Colombia, in 1968, was considered the "Second Vatican Council in Latin America", as it inculturated the new continent. This article takes, from the third chapter of the Conference (family and demography), the topic of the family as: formative of persons, educator in the faith and promoter of development, and selects five key concepts (salvation, holiness, sacramental life, unity and community of faith), to then make a parallel with the ecclesiological models of the ecclesiology treatise on ecclesiology proposed by the Second Vatican Council; finally, it proposes the Latin American family as an ecclesiological model that faces the challenges posed by the 21st century.

Keywords: Latin American family, Second General Conference of the Latin American Episcopate, Second Vatican Council, ecclesiological model, ecclesiology, 21st century.
\end{abstract}

\section{Conferência de Medellín e a família latino-americana. Modelo eclesiológico como novo paradigma para o século xxI}

\section{Resumo}

A II Conferência Geral dos Episcopados Latino-Americanos realizada na cidade de Medellín-Colômbia, no ano de 1968, foi considerada “O Concílio Vaticano II na América Latina", porque o inculturou no novo continente. Baseado no capítulo iII (família e demografia), este artigo aborda o tema da família como formadora de pessoas, educadora na fé e promotora do desenvolvimento e seleciona cinco conceitos-chave (salvação, santidade, vida sacramental, unidade e comunidade de fé ) para, posteriormente, fazer um paralelo com os modelos eclesiológicos do tratado de eclesiologia proposto pelo Concílio Vaticano II; finalmente, propõe que a família latino-americana é o modelo eclesiológico que enfrenta os desafios do século xxi e apresenta algumas conclusões.

Palavras-chave: família latino-americana, Segunda Conferência Geral dos Episcopados Latino-Americanos, modelo eclesiológico, eclesiologia, século XxI. 


\section{Introducción}

No es fácil, por varias razones, una reflexión sobre la familia en América Latina. Primero, porque la idea de familia se encarna en realidades sociológicas sumamente diversas y, segundo, porque la familia ha sufrido, tal vez más que otras instituciones, los impactos de las mudanzas y transformaciones sociales (Celam, 1968, III-1).

La Segunda Conferencia General del Episcopado Latinoamericano, celebrada en la ciudad de Medellín, Colombia, en el año de 1968, fue la razón por la cual diversas facultades de teología de las universidades de América Latina, Centro América y el Caribe se reunieron en el año 2018 (realizando diversos eventos, conferencias, congresos y simposios) para conmemorar los 50 años de su realización.

Hoy, tras 52 años de haberse llevado a cabo dicho evento y frente a las nuevas adversidades que está afrontando la humanidad por la pandemia del covid-19, el núcleo familiar ha adquirido de nuevo gran protagonismo en todas las culturas y religiones del mundo, pues, en los momentos de aislamiento obligatorio, ha sido el hogar el refugio del hombre.

Es por esta razón que este artículo pretende rescatar las facetas que considera relevantes de la familia, de acuerdo con la Conferencia, y algunos conceptos clave de esta, para hacer un paralelo con los modelos eclesiológicos del Concilio Vaticano II y, de esta manera, responder a la siguiente pregunta: ¿a partir de la Conferencia de Medellín y el cambio de paradigma de la sociedad actual, puede ser la familia Latinoamericana un modelo eclesiológico que pueda afrontar los retos propuestos por el siglo xxI?

A continuación, y para dar respuesta a esta inquietud, este artículo consta de tres momentos. El primer momento es una breve contextualización eclesial de la década de 1960. El segundo momento se enfoca en la familia y algunas fuentes de la teología. El tercer momento se refiere a la Conferencia de Medellín y a la familia latinoamericana: modelo eclesiológico que puede afrontar los retos del siglo xxi y que sirve para realizar un paralelo con los conceptos de eclesiología del Concilio Vaticano II. Al finalizar, el artículo presenta las conclusiones.

\section{Breve contextualización eclesial de la década de 1960}

Los años 1960 fueron decisivos para la historia de la humanidad, los diferentes movimientos de carácter social y eclesial, además de los avances científicos en todas las áreas del conocimiento, incluyendo las ciencias humanas y sociales, 
hicieron que la sociedad enfrentara un cambio de modelo. Nuevas actitudes, comportamientos y valores se abrían paso en el medio, puesto que el mundo avanzaba a pasos agigantados hacía un nuevo milenio.

Hacer una descripción detallada de todos los eventos que sucedieron durante esta década sería un trabajo sumamente extenso; por lo tanto, este escrito se limita a tocar, puntalmente y de forma sucinta, los momentos eclesiales más relevantes de estos diez años; pues estos determinaron el rumbo que tomaría la Iglesia de cara hacia el futuro.

La realización del gran Concilio Vaticano II (1962 1965), convocado por el papa Juan XXIII y finalizado por el papa Pablo VI, es considerado como el evento eclesial más importante del siglo $\mathrm{xx}$, iniciando un "despertar" en la Iglesia, que interpretaba los "signos de los tiempos", usando las palabras de Mesa (2016):

En efecto, todo el revuelo que había generado el Concilio le estaba dando a la Iglesia católica "un nuevo aire". Desde allí, la forma de hacer teología se ve enfrentada a la realidad que vivía el mundo. De este modo, la Iglesia afrontaba una serie de retos, para poder salir de ese estancamiento que la había hecho quedarse suspendida en el tiempo, como en una especie de "letargo". [...] el hombre del siglo xx, [...] [como] también el de futuras generaciones, necesitaba más que nunca sentirse pueblo de Dios y sentir que la Iglesia iba de la mano con él, acompañando y actuando de manera eficaz en sus realidades. (p. 197)

El Concilio generó un cambio de paradigma en la teología (giro antropológico) que empezó a ver al hombre en su relación con Dios y con los demás seres humanos. También se promulgó la encíclica del papa Pablo VI, Populorom Progresio (1967), que trata "sobre la necesidad de promover el desarrollo de los pueblos" y es el abrebocas de la Segunda Conferencia General del Episcopado Latinoamericano realizada en Medellín en 1968, que sería llamada "el Concilio Vaticano II en América Latina", como ya dijimos anteriormente, y en la que nació la teología de la liberación, cuyo gran aporte es una iglesia pobre para los pobres.

Para hilar los argumentos y comprender la importancia del tema de la familia, se mostrará desde las fuentes de la teología (Sagrada Escritura, Tradición y Magisterio) la importancia del núcleo fundamental de la sociedad humana y, como señalamos antes, se desarrollarán los puntos relevantes de dicha conferencia, que se hacen pertinentes para el tema de este texto. 


\section{Familia y fuentes de la teología}

En este segundo momento, se hace una definición teológica muy concisa de la familia y se toman algunas citas de las fuentes de la teología, por lo menos las que se consideran más representativas, para que den algunas luces sobre el contexto actual. Ahora bien, una de las explicaciones más bellas sobre el concepto familia, la hace Vidal (2014), quien considera que:

La familia es un "icono de la Trinidad". "Dios es amor $(1$ Jn 4, 8) y vive en sí mismo un misterio de comunión personal de amor"; a imagen y semejanza de ese misterio de comunión es constituida la realidad humana y, de modo especial, la realidad humana en su condición personal y comunicativa. La familia sigue siendo, pese a todas las diferencias evidentes, el icono de la Trinidad más evidente. (p. 44)

En lo que respecta a las fuentes de la teología, comenzaremos, como es debido, con la Sagrada Escritura, Xavier Pikaza (2007) comenta que se puede evidenciar en el Antiguo Testamento una familia definida desde el punto de vista patriarcal:

Garantiza la elección y las promesas: ellos (Abrahán, Isaac, Jacob y los Doce) definen el surgimiento del pueblo. Estos padres de familia formaban el consejo de ancianos, [...] que fueron la autoridad definitiva (y casi única) en la federación de tribus: eran los representantes de familia y clanes, que forman la asamblea permanente (legislativa, ejecutiva, judicial) del pueblo (Ex 3, 16; Nm 11, 16; Dt $5,23)$. [...] Cada familia repite y encarna el modelo patriarcal, con el padre varón como garante de Dios y transmisor de las promesas, en línea genealógica. (p. 379)

Es evidente que el origen de la vida para el pueblo judío tenía una connotación humana, es decir, natural y al mismo tiempo divina, por ser el mismo Dios quien la otorga como una fuente de bendición y signo de su alianza. Debido a esto, como lo expresan Aros y Basualto (2014), se entiende:

La procreación como un mandato de Yahveh para ellos (Gn 1, 28; 35, 11); que los hijos sean valorados como un don maravilloso de Dios (Sal 217, 3-5a) y que, por esta misma razón, las familias y el pueblo busque tener una descendencia 
numerosa (Gn 24,60), ya que se ve en esto el cumplimiento concreto de la promesa que Dios hizo a Abraham (Gn 17, 3). (p. 175)

El Nuevo Testamento manifiesta una gran novedad, que Corpas (2015) presenta de la siguiente forma:

El evangelio proponía era vivir las relaciones familiares "en el Señor" que es el sentido de las recomendaciones de las cartas a los fieles de Éfeso y a los Colosenses (Ef 5, 21-6, 9; Col 3, 18-21) y las de la Primera de Pedro (1 Pe 3, 17) en cuanto aplicaciones concretas de la novedad del evangelio a la vida familiar. Conocidas como "tabillas domésticas [...] establecían cómo se debía vivir la relación esposo-esposa, la relación padres-hijos, la relación amos-esclavos. [...] Simplemente las ilumina con la novedad del evangelio. (pp. 21-22).

Los Padres de la Iglesia también reflexionaron sobre la familia, pues no solo contemplaron los lazos de consanguinidad, sino también los comunitarios. Mira (2015), citando a Juan Crisóstomo, hace una representación de la familia, teniendo en cuenta:

Diversas imágenes: como una cuidad, en la que hay autoridad y un orden que debe ser respetado, como un ejército en el que se vive una severa disciplina que prepara para la batalla; como una palestra en la que se recibe educación; como una iglesia en la que todos rezan juntos y en la que el padre transmite a los demás en las reuniones familiares las enseñanzas que ha recibido en la Iglesia. (p. 108)

Flecha (1991), hace énfasis en el pensamiento de san Agustín que elabora una comparación de familia con los ministros de la Iglesia. “San Agustín invita a los padres a hacer en el hogar las veces del obispo, [...] precisamente por ejercer en su iglesia el mismo cuidado de supervisión que los padres deberán ejercer en sus casas" (p. 38).

Recogiendo lo más importante del Concilio Vaticano II sobre el tema de la familia, Corpas (2015) manifiesta que este ocupó un lugar significativo y se orientó:

En la línea de la antropología personalista que sirvió de fundamento a sus lineamientos pastorales, acuñó la definición de la familia como "intima comunidad de vida y amor" (GS 48) al mismo tiempo que, en perspectiva eclesiológica, 
recordó la antigua expresión "iglesia doméstica" (LG 11) con la que el Nuevo Testamento (Ro 16, 5) y San Crisóstomo (In Epist. Ad Eph) se había referido a la familia. (p. 22)

Otra definición bien importante sobre este concepto, la hace el Catecismo de la Iglesia Católica en el numeral 2207, donde se afirma lo siguiente:

La familia es la célula original de la vida social. Es la sociedad natural en que el hombre y la mujer son llamados al don de sí en el amor y en el don de la vida. La autoridad, estabilidad y la vida de relación en el seno de la familia constituyen los fundamentos de la libertad, de la seguridad, de la fraternidad en el seno de la sociedad. La familia es la comunidad en la que, desde la infancia, se pueden aprender los valores morales, se comienza a honrar a Dios y a usar bien de la libertad. La vida de familia es iniciación a la vida en sociedad. (La Santa Sede, 1992, n. $\left.{ }^{\circ} 2207\right)$

Para finalizar este segundo momento, vale la pena mencionar algunos de los documentos del Magisterio de la Iglesia sobre la familia que han querido responder a las problemáticas que ha surgido en los últimos tiempos. Entre ellos encontramos la encíclica Humanae Vitae (1968) y la exhortación apostólica Evangelii Nuntiandi (1975) del papa Pablo VI; la exhortación apostólica Familiaris Consortio (1981) y la carta a las familias Gratissimam Sane (1994) del papa Juan Pablo II; la encíclica Deus Caritas Est (2005) y la encíclica Caritas in Veritate (2009) del papa Benedicto XVI y la exhortación apostólica Amoris Laetitia (2016) del papa Francisco.

\section{Conferencia de Medellín y familia latinoamericana: un modelo eclesiológico para el siglo xxI}

La Conferencia de Medellín presenta a la familia como "formadora de personas, educadora en la fe [y] promotora del desarrollo" (Celam, 1968, III-5-6-7); es por esta razón que en este punto se tomarán estas hipótesis como puntos clave, se seleccionarán los conceptos salvación, santidad, vida sacramental, unidad y comunidad de fe para encauzar la reflexión y se hará un pequeño paralelo con los modelos eclesiológicos propuestos por el tratado de eclesiología formulado por el Concilio Vaticano II. Lo anterior nos permitirá comprender las formas en las que la institución familiar latinoamericana puede afrontar los retos propuestos por el siglo xxI y, de esta manera, reconocerse como núcleo primigenio de la 
sociedad que tiene múltiples responsabilidades éticas, morales y de orden espiritual; entre ellas, lograr una formación integral en todas las dimensiones del ser humano, que es imagen de Dios, $y$, en estos momentos de crisis que afronta la humanidad entera, retomar el protagonismo que nunca debió haber perdido, para, así, convertirse de nuevo en fundamento real de la constitución y educación de la persona humana y de la sociedad.

Así pues, la Conferencia afirma que "es por tanto necesario tener en cuenta la doctrina de la Iglesia para fijar una acción pastoral que lleve a la familia latinoamericana a conservar o adquirir los valores fundamentales que la capacitan para cumplir su misión" (Celam, 1968, III-4).

\section{Familia formadora de personas}

Indiscutiblemente, es la familia el lugar en donde la persona humana adquiere su condición de ser única e irrepetible; de ahí que la constante relación del hombre con el hombre, desde el seno familiar, le haga una comunidad unida por el vínculo del amor interpersonal. La familia como institución debe ser capaz de formar personas que puedan cambiar la realidad de los contextos sociales en los que se desarrollan, personas con carácter, suficientemente capacitados para tomar las riendas de la sociedad con responsabilidad, respeto y dignidad.

\section{Familia educadora en la fe}

Los hijos, fruto de la bendición de Dios, hacen que la familia deba ejercer una paternidad responsable que se da en el amor. Es así como debe ser educadora en todos los aspectos de la vida del hombre. Principalmente, debe ser garante de la educación en la fe $\mathrm{y}$, de esta manera, mostrar su fidelidad al proyecto establecido por Dios. Mejor dicho, educar en la fe debe ser tarea primordial para los padres, ya que de esta manera se puede garantizar que los hombres y mujeres del futuro puedan ser personas integrales, formadas en el respeto y amor a Dios y a su prójimo, y, por ende, obtener una sociedad justa y equitativa.

\section{Familia promotora de desarrollo}

La familia latinoamericana debe ser promotora del desarrollo social, cultivando preponderantemente en sus miembros una serie de valores éticos y morales, como lo son la responsabilidad, equidad, solidaridad, libertad y paz, que les den 
herramientas para transformar la sociedad, que sufre de pobreza, desigualdad, injusticia y violencia social e intrafamiliar, además de una creciente secularización que ha hecho que esta pierda el humanismo cristiano que hace al hombre ser capaz de Dios y del otro.

\title{
Paralelo de la Conferencia de Medellín y los modelos eclesiológicos propuestos por el Concilio Vaticano II
}

Es importante, en el contexto descrito en el apartado anterior, realizar una propuesta teológica partiendo de un pequeño paralelo entre la Conferencia y los nuevos modelos eclesiológicos propuestos por el Concilio Vaticano II, utilizando algunos conceptos claves, mencionados anteriormente, de la eclesiología.

Al mencionar los términos "salvación" y "santidad" (Celam, 1968, III-6), la Conferencia cita la constitución pastoral Gaudium et Spes, (1965), donde se hace una clara invitación a los padres para que, por medio del testimonio y la oración, los demás miembros de la familia puedan descubrir el propósito de la existencia que solo viene de Dios. Por otra parte, este mismo documento expone:

\begin{abstract}
Al buscar su propio fin de salvación, la Iglesia no solo comunica la vida divina al hombre, [...] elevando la dignidad de la persona, consolidando la firmeza de la sociedad y dotando a la actividad diaria de la humanidad de un sentido y de una significación mucho más profundos. (Pablo VI, 1965, nº.40)
\end{abstract}

El amor en la pareja tiene una identidad propia, es decir son la "imagen del Dios" y, por lo tanto, ambos esta llamados a la santidad, permaneciendo en fidelidad, en un solo corazón, para vivir como auténticos cristianos en el seguimiento de Cristo. De esta manera, como lo enseña la constitución dogmática Lumen Gentium en su numeral 11:

[...] todos los fieles, cristianos, de cualquier condición y estado, fortalecidos con tantos y tan poderosos medios de salvación, son llamados por el Señor, cada uno por su camino, a la perfección de aquella santidad con la que es perfecto el mismo Padre. (Pablo VI, 1964a, n. ${ }^{\circ} 11$ )

Otro término es la "vida sacramental" (Celam, 1968, III-11), que la Conferencia menciona cuando hace énfasis en el matrimonio como "un camino para la 
progresiva maduración humana y cristiana" (Celam, 1968, III-11c), igualmente la eclesiología muestra a la Iglesia como

[...] sacramento de salvación; en efecto, desde una perspectiva trinitaria e histórico-salvífica, la Iglesia se presenta como el lugar en el que se concentra la acción de Dios en favor de los hombres, que actualiza en el presente el evento salvífico y proyecta su perfección final de los tiempos. El concepto de "sacramento" pone de manifiesto el carácter divino y humano de la Iglesia, que es un misterio en su esencia más profunda, porque lo divino escapa a la comprensión humana y porque lo humano a veces oscurece la realidad divina. (Niño, 2006, p. 77)

El concepto de "unidad" (Celam, 1968, III-17), en la eclesiología, contiene un significado profundo; tomando las palabras del decreto Unitatis Redintegratio en el numeral 813, "la Iglesia es una debido a su origen: El modelo y principio supremo de este misterio es la unidad de un solo Dios Padre e Hijo en el Espíritu Santo, en la Trinidad de personas" (Pablo VI, 1964b, n. ${ }^{\circ} 813$ ).

Cabe resaltar también, lo que expresa Niño (2006): "la unidad que Dios crea en la Iglesia no es uniformidad; cuanto don, gracia suya, es recibida por los hombres que forman la Iglesia como sujetos vivos que tienen una historia y una libertad propia" (p. 119), por esto, la diversidad de sus miembros no se convierte en un obstáculo para su misión; sino por el contrario, la enriquecen en todos sus aspectos, por tal motivo "la Iglesia aparece como "un pueblo reunido en virtud de la unidad del Padre y del Hijo y del Espíritu Santo" (Lumen Gentium, 4).

Ahora bien, esta unidad a semejanza de la Trinidad debe ser el modelo de las familias latinoamericanas, el documento de la Conferencia hace una invitación a la pastoral familiar e invita a "despertar en los esposos la necesidad del diálogo conyugal que los lleve a una unidad profunda y a un espíritu de corresponsabilidad y colaboración" (Celam, 1968, III-17).

En lo que se refiere a la "comunidad de fe", se puede afirmar con plena certeza que en la Trinidad se encuentra el ejemplo de toda familia, la cual tiene la misión de conservar la unidad y reflejar la imagen de Dios. De ahí que, el papa san Juan Pablo II, en la exhortación apostólica postsinodal Christifideles Laici, de 1988, manifieste que

La comunión de los cristianos con Jesús tiene como modelo, fuente y meta la misma comunión del Hijo con el Padre en el don del Espíritu Santo: los cristianos se unen al Padre al unirse al Hijo en el vínculo amoroso del Espíritu. (II-18) 
Por otro lado, la constitución dogmática Lumen Gentium (1964), en el numeral 11, haciendo énfasis en el tema de la familia como comunidad, expresa lo siguiente:

De este consorcio procede la familia, en la que nacen nuevos ciudadanos de la sociedad humana, quienes, por la gracia del Espíritu Santo, quedan constituidos en el bautismo hijos de Dios, que perpetuarán a través del tiempo el Pueblo de Dios. En esta especie de Iglesia doméstica los padres deben ser para sus hijos los primeros predicadores de la fe, mediante la palabra y el ejemplo, y deben fomentar la vocación propia de cada uno, pero con un cuidado especial la vocación sagrada. (Pablo VI, 1964a, n. ${ }^{\circ} 11$ )

En definitiva, una eclesiología enfocada en la familia debe elaborarse a partir de la Iglesia, que debe salir al encuentro de todos los fieles para crear espacios de dialogo, formación y catequesis, elaborando una pastoral adecuada que abra las puertas con el fin de brindarle a las creyentes oportunidades de crecimiento; mejor dicho, donde puedan asumir la responsabilidad de guiar y acompañar a cada una de las tipologías familiares existentes, acogiendo desde la misericordia de Dios la realidad presente y procurando una cercanía que les invite a participar activamente de los sacramentos, la oración y el compartir común en los diferentes grupos eclesiales que fortalecen la vida y el espíritu.

\section{Retos y desafíos para el siglo xxI}

Si bien la Conferencia describió la problemática que debían enfrentar las familias, también identificó diversas realidades que no podían pasar desapercibidas para la Iglesia, incluso, propuso una acción pastoral ante los cambios que afectaban las instituciones familiares.

Es evidente que, en la actualidad, las dificultades presentadas por este documento han avanzado aceleradamente; se han incrementado los nacimientos en condiciones de pobreza, los divorcios, las uniones de parejas del mismo sexo, el secularismo, la ausencia de los padres en la crianza de sus hijos, la desigualdad social (sin atender a las necesidades de los más pobres), el consumismo, la falta de oportunidades laborales y económicas y, al mismo tiempo, se han perdido los valores tradicionales, el interés por construir familias sólidas y las relaciones interpersonales (que pasaron al individualismo por las nuevas tecnologías), que 
han roto el diálogo y la fraternidad; todo esto ha ido deteriorando paulatinamente al foco primigenio de la sociedad.

Así pues, la familia cristiana en el siglo xxi, bajo los nuevos paradigmas que enfrenta la sociedad, ha ido transformado su tipología y se han generado muchos cambios en su estructura tradicional. Los nuevos "signos de los tiempos" han transmutado la realidad familiar, haciendo que se deban considerar diferentes prototipos de familias que, por sus condiciones atípicas, no deben dejar de considerarse ni se pueden excluir, porque el misterio divino también actúa en ellas.

Como lo hace notar Botero (2009):

Dentro de esta diversidad de familias, las más frecuentes en Occidente parecen ser estas: la familia tradicional y la familia nuclear; los viudos (as) con familia, los divorciados y los divorciados vueltos a casar o familias recompuestas; las parejas que han adoptado niños, las madres solteras, las parejas que han tenido hijos a través de la fecundación 'in vitro' o fecundación asistida, las familias de huérfanos, las parejas 'gay' con adopción, las parejas formadas por 'transexuales', las parejas unidas por simple unión consensual o por matrimonio civil, las 'comunas' de familias que conoció el régimen comunista en su tiempo, etc. Estos tipos de familia continuarán aumentando en virtud del clima de 'permisivismo' social y jurídico que reina en el ambiente presente. (p. 10)

Entonces, indudablemente, el núcleo familiar se ha visto transformado desde todas las realidades sociales del mundo actual. El mismo autor, citando a Cooper y a Zorokin, comenta que ellos miran a esta institución con un enfoque pesimista:

Cooper, por ejemplo, llegó a prever ‘la muerte de la familia y Zorokin afirmaba en la primera mitad del siglo xx que después de unas pocas décadas, se llegaría a concebir la casa de la familia simplemente como un "parqueadero nocturno". No obstante, estos pronósticos y los cambios que han debido soportar la familia, esta ha llegado al siglo xxi; el mismo Cooper años después de anunciar "la muerte de la familia" debió retratarse y afirmar que la familia no muere, la familia se renueva. (Botero, 2009, p. 20)

Las familias están llamadas a despertar de su aletargamiento, a renovarse interiormente de forma progresiva y, sobre todo, a comprometerse consigo mismas para construir relaciones profundas y estables, que les permita caminar juntos en los momentos de gozo, especialmente en la adversidad para cumplir así su 
misión de vivir en continua santidad y unidad como lo propone la exhortación apostólica del papa Francisco Gaudete et Exsultate, en el numeral 6, donde nos recuerda que:

Nadie se salva solo, como individuo aislado, sino que Dios nos atrae tomando en cuenta la compleja trama de relaciones interpersonales que se establecen en la comunidad humana: Dios quiso entrar en una dinámica popular, en la dinámica de un pueblo. $\left(2018\right.$, n. $\left.^{\circ} 6\right)$

Por otra parte, la Iglesia y su ministros, teólogos, religiosos y laicos necesitan dejar su zona de confort, es decir, no quedarse solo con enseñar la doctrina y el Evangelio, pues se requiere una pastoral en salida donde se pueda hacer un acompañamiento a matrimonios y a familias de cualquier tipología, sin juzgar ni señalar, sino más bien, escuchando y acompañando para sanar tantas heridas que les impide caminar hacia Cristo, iluminando el entorno con la esperanza desde la pascua, que es el eterno presente que siempre se actualiza.

Para que todos puedan colaborar en esta tarea, es importante una formación que brinde las bases para un acompañamiento oportuno. El papa Francisco, en la constitución apostólica Veritatis Gaudium en el numeral 1, manifiesta que:

El vasto y multiforme sistema de los estudios eclesiásticos ha florecido a lo largo de los siglos gracias a la sabiduría del Pueblo de Dios, que el Espíritu Santo guía a través del diálogo y discernimiento de los signos de los tiempos y de las diferentes expresiones culturales. Dicho sistema está unido estrechamente a la misión evangelizadora de la Iglesia y, más aún, brota de su misma identidad, que está consagrada totalmente a promover el crecimiento auténtico e integral de la familia humana hasta su plenitud definitiva en Dios. (Francisco, 2017, n. ${ }^{\circ}$ 1)

La vida sacramental de la Iglesia es para la familia un camino de maduración, en medio de un proceso dinámico que actualiza el presente e impulsa en medio de las debilidades humanas a la perfección eterna; como lo manifiesta la exhortación apostólica postsinodal Amoris Laetitia en el numeral 325:

Ninguna familia es una realidad celestial y confeccionada de una vez para siempre, sino que requiere una progresiva maduración de su capacidad de amar. Hay un llamado constante que viene de la comunión plena de la Trinidad, de la unión preciosa entre Cristo y su Iglesia, de esa comunidad tan bella que es la 
familia de Nazaret y de la fraternidad sin manchas que existe entre los santos del cielo. (Francisco, 2016, n. ${ }^{\circ}$ 325)

\section{Conclusiones}

Es fundamental mencionar las recomendaciones de la Conferencia, donde se propone una acción pastoral para la familia, la cual ha de convertirse en la actualidad en palabras vivas, que, aunque se escribieron en el pasado, siguen siendo de gran utilidad, así, es importante que, no solo de la Iglesia, sino también del gobierno, "establezcan una legislación y una sana y actualizada política familiar" (Celam, 1968, I-8), para que logren una organización que les brinde una mejor calidad de vida.

Con respecto a la Iglesia, esta debe ofrecer a las parejas una sólida educación en una preparación integral donde se fomente el dialogo, la unidad y la corresponsabilidad, para los que quieren unirse en el sacramento del matrimonio, especialmente los que son más jóvenes, logren comprender la convicción de la paternidad responsable. Al mismo tiempo, es necesario comunicar una espiritualidad laical y una continua invitación a la apertura con otras familias, siendo generosas inclusive con quienes hacen parte de otras confesiones y con aquellas que sufren violencia, miseria, pobreza y no cuentan con las oportunidades para las necesidades básicas.

El reto de hoy es que toda familia tenga su mirada en el mejor modelo, que es Dios Uno y Trino, para que, a semejanza de esta comunidad perfecta, todos los miembros de esta alcancen la santidad y, con la ayuda del obispo y sus ministros y apoyados en el laicado, puedan iluminar la realidad humana y dar a conocer el plan salvífico de Dios.

El desafío más grande es permanecer vigilantes en esta continua evolución, escuchando en discernimiento y oración los "signos de los tiempos" pero no con indiferencia, si no con el deseo de involucrarse sencillamente y con la ayuda del Espíritu Santo, que seguirá impulsando a todos los fieles, para que con amor y responsabilidad acompañen estas realidades con el fin de alcanzar la santidad y la salvación de la Iglesia doméstica.

No se trata de imponer la doctrina al pie de la letra, sino de introducirla con los pies descalzos en la tierra sagrada del corazón del prójimo, con la caridad y el testimonio, de lo contrario, las personas, al experimentar la imposición, el rechazo y la exclusión se alejaran y no querrán regresar al seno de la Iglesia; por lo 
tanto, es necesario tener los mismos sentimientos de Cristo, (Filipenses 2, 5) que transforma la humanidad, le devuelve el sentido y cura las heridas, restableciendo los vínculos quebrantados.

Cabe resaltar que en todos los seres humanos se manifiesta la acción de Dios, porque el Padre los acogió como suyos el día del bautismo, los amó hasta el extremo en la muerte de su Hijo, que se entregó por todos sin excepción, y les envió la compañía de su Espíritu para todos los momentos de la vida. Es verdad que muchos rechazan esta bellísima dignidad, pero este ha sido el sello, la alianza y el corazón de la Trinidad, que ama sin condiciones a pesar del pecado y la libertad humana, que hacen que se pierda la verdadera esencia.

La Iglesia debe custodiar la unidad entre los creyentes, sin permitir que alguno de sus miembros sea excluido, que se juzgue la diferencia del otro o que se señalen sus equivocaciones, sino que por el contrario, debe, mediante su misión profética, denunciar lo que se opone a la voluntad de Dios, $\mathrm{y}$, sobre todo, esforzarse por acoger con respeto, tolerancia y misericordia a quienes se ha desviado del camino, ofreciendo todos los medios oportunos para la salvación y saliendo a buscar las ovejas para llevarlas nuevamente al redil, para que encuentren la vocación y la misión a la cual están llamados en la sociedad y la asuman con total disponibilidad, siendo formadoras de personas, educadoras de la fe y promotoras de desarrollo.

Hoy más que nunca las familias latinoamericanas atraviesan grandes cambios provocados por la gran crisis económica, social y de salud que ha traído la pandemia del covid-19, cada día hay más pobres, más hambrientos, más necesitados y más muertos; se deben asumir día tras día muchos más problemas que en ocasiones absorben a las familias y les hacen ver que el camino no tiene salida; por este motivo, la Iglesia debe estar presente en ellas, en los momentos más importantes de la vida de todos sus miembros; la Iglesia está llamada a estar siempre dispuesta a ser luz, animar, fortalecer, orientar y ser voz de esperanza en momentos de desesperanza para quienes han perdido todo, incluso la fe, que es el don más preciado.

La Iglesia y el Estado deberán hablar el mismo lenguaje que la familia, teniendo que cuenta que ambas instituciones deben asumir los retos de hoy, cada una con lo que le corresponde; debe existir una mutua colaboración entre ambos estamentos, y con otras entidades que velen por los derechos de la familia, para que quienes enfrentan el desplazamiento, el desempleo, el maltrato, la enfermedad, la crisis matrimonial, la orfandad, emigración, la pobreza, etc., se sientan respaldados y protegidos. Para esto se requiere dejar de lado los intereses 
personales e individuales para pensar en las personas que sufren, de lo contrario será imposible que el Espíritu Santo haga su obra e indique el camino correcto para enfrentar los desafíos que ahogan la realidad familiar, que pide a gritos resurgir de las cenizas para construir una nueva historia de esperanza.

\section{Referencias}

Aros, J. y Basualto, L. (2014). Aportes a la teología de la familia. Lectura eclesiológica de la Iglesia doméstica. Veritas, (30), 163-183.

Botero, S. (2009). La familia cristiana. Misterio humano y divino. Editorial Espigas.

Celam. (1968). II Conferencia General del Episcopado Latinoamericano. La Iglesia en la actual transformación de América Latina a la luz del Concilio. Celam.

Corpas, I. (2015). Teología y Familia: ¿Cómo se expresa Dios en esta diversidad de configuraciones? Actas Teológicas (Universidad Católica De Temuco), 20(1), 7-38. http:// derechoycienciapolitica.cl/index.php/actasteologicas/article/viewFile/1006/_3

Flecha, J. (1991). La familia como lugar eclesial. Misión Abierta, (1), 32-48.

Francisco. (2018). Exhortación Apostólica Gaudete et Exsultate del santo padre Francisco sobre el llamado a la santidad en el mundo actual. Libreria Editrice Vaticana. http:// w2.vatican.va/content/francesco/es/apost_exhortations/documents/papa-francesco_esortazione-ap_20180319_gaudete-et-exsultate.html

Francisco. (2017). Constitución apostólica Veritatis Gaudium sobre las universidades y facultades eclesiásticas. Libreria Editrice Vaticana. http://w2.vatican.va/content/ francesco/es/apost_constitutions/documents/papa-francesco_costituzioneap_20171208_veritatis-gaudium.html

Francisco. (2016). Exhortación apostólica postsinodal Amoris Laetitia del santo padre Francisco a los obispos, a los presbiteros y diáconos, a las personas consagradas, a los esposos cristianos y a todos los fieles laicos sobre el amor en la familia. Libreria Editrice Vaticana http://w2.vatican.va/content/francesco/es/apost_exhortations/documents/ papa-francesco_esortazione-ap_20160319_amoris-laetitia.html

Juan Pablo II. (1988). Exhortación apostólica postsinodal Christifideles Laici de sus santidad Juan Pablo II sobre vocación y misión de los laicos en la iglesia y en el mundo. Libreria Editrice Vaticana. http://w2.vatican.va/content/john-paul-ii/es/apost_exhortations/documents/hf_jp-ii_exh_30121988_christifideles-laici.html

La Santa Sede. (1992). Catecismo de la Iglesia católica. La Santa Sede http://www.vatican. va/archive/catechism_sp/index_sp.html

Mesa, P. (2016). Gaudium et Spes: giro antropológico y nuevos retos de la teología en la secularización del mundo de hoy. En A. Castrillón (Comp.), Jornadas de reflexión filosófica y teológica. Pensar la actualidad (pp. 195-205). Fondo Editorial Luis Amigó. 
Mira, M. (2015). Matrimonio y familia en los Padres de la Iglesia. Scripta Theologica, 47(1), 89-110.

Niño, F. (2006). Eclesiología. Editorial Pontificia Universidad Javeriana.

Pablo VI. (1965). Constitución pastoral Gaudium et Spes sobre la Iglesia en el mundo actual. La Santa Sede. http://www.vatican.va/archive/hist_councils/ii_vatican_council/ documents/vat-ii_const_19651207_gaudium-et-spes_sp.html

Pablo VI. (1964a). Constitución dogmática sobre la Iglesia Lumen Gentium. La Santa Sede. http://www.vatican.va/archive/hist_councils/ii_vatican_council/documents/ vat-ii_const_19641121_lumen-gentium_sp.html

Pablo VI. (1964b). Decreto Unitatis Redintegratio. La Santa Sede. https://www.vatican. va/archive/hist_councils/ii_vatican_council/documents/vat-ii_decree_19641121_ unitatis-redintegratio_sp.html

Pikaza, X. (2007). Diccionario de la Biblia. Historia y palabra. Editores Verbo Divino.

Vidal, M. (2014). Teología de la familia. Familia. Revista de Ciencias y Orientación Familiar, (49), 43-52. 